\title{
Potestas and the language of power: Conceptualising an approach to Power and Discernment politeness in ancient languages
}

\begin{abstract}
:
The concept of "Discernment politeness" stems from research undertaken in the 1980s on the Japanese phenomenon of wakimae. Since the earliest work on the phenomenon by Hill et al. (1986) and Ide (1989, 1992), many scholars have looked to further explore Discernment across cultures (i.e. Kádár and Mills 2013; Kádár and Paternoster 2015; Ridealgh and Jucker 2019). Fundamentally, Discernment has been approached as expected (and quasi-mandatory) behavioural norms used by subordinates towards their superiors within a communicative act, dictated by the socio-cultural context of the interaction (Ridealgh and Jucker 2019). What becomes apparent, when studying ancient languages, is that due to the hierarchical nature of remote societies, Discernment includes a complementary dimension, an opposing phenomenon to deference, equally visible in interpersonal interactions, which has its foundation within the Power variable. This paper explores this opposing phenomenon (i.e. expected or permitted language used by superiors to their subordinates as a manifestation of their Power), which we call "Potestas", within the context of Late Egyptian and Old Latin, in order to highlight the phenomenon, its forms of expression in these two languages, the gaps in regards to the Power variable within traditional politeness approaches, and its relationship with (Im)politeness Research.
\end{abstract}

\section{Introduction ${ }^{1}$}

A potential problem we face when studying politeness in ancient languages (by ancient we refer to those languages and cultures which existed during the BCE period; Kádár and Ridealgh 2019: 176) is that traditional politeness approaches often consider the social variable of Power as both negotiable (Locher 2015: 6) and being viewed equally with social Distance in analyses (e.g., Conlan 2005). The challenge with ancient languages is that for the firmly hierarchical societies of the ancient world, Power, for the most part, was a fixed phenomenon and not negotiated between interlocutors within interactions. It is also a difficult task to view Power in conjunction with social Distance, when so much essential relational information is either missing or fragmented. This paper seeks to develop the role that Power should play within a theory of (im)politeness, especially when dealing with ancient linguacultures, and by doing so looks to highlight some of the gaps within traditional approaches when it comes to the impact Power can have within a relationship dynamic. Approaching this topic from the concept of Discernment politeness, which is usually applied to explain the dyadic relationship between subordinate and superior, we will argue that Power supports a pre-patterned discursive practice of superiors towards their subordinates. According to this pattern, the high-Power individual does not need to satisfy the facewants of the low-Power individual, and although this could be perceived as a Face-Threatening Act (henceforth FTA) outside of this specific dynamic, this action does not affect the successful continuation

\footnotetext{
${ }^{1}$ Many thanks to the reviewers of this article and to Professor Andreas Jucker, for their insightful comments, further improving this paper.
} 
of the broader relationship. If we understand "discernment" as "the socially dominant norms of relationally constructive conventional and ritualistic behaviour" (Kádár and Mills 2013: 143), which has its roots within the perceived dynamic of the relationship, we cannot overlook the superior-subordinate dynamic, an interpersonal scenario that has not received much attention in the theorisation of politeness, likely because the kind of linguistic behaviour characteristic of superiors (or better put, the linguistic behaviour that reveals hierarchical superiority) has traditionally been understood as being opposite to politeness.

Thus, our claim in this paper will be that there is a distinct opposing phenomenon to deference, a linguistic behavioural pattern that we call "Potestas", which helps to index the superior-subordinate dynamic. This complementary phenomenon functions contrarily but comparably to deference, in regard to how it minimalizes facework and prioritises social status. Although Potestas cannot be considered, strictly speaking, a polite phenomenon in itself, nor a manifestation of impoliteness, it should be taken into account within a theory of (im)politeness, in particular one that looks to reflect the sociolinguistic features of ancient linguacultures.

We will utilise evidence from two ancient languages, Late Egyptian and Old Latin, to demonstrate the role Potestas plays in relationships with a clear Power imbalance. Both deference and Potestas, as the two sides of the same coin, are particularly applicable to historically remote languages and cultures due to the marked hierarchical nature of these societies. An important point to address in this paper is that although deference is fully incorporated into $(\mathrm{Im})$ politeness Research (especially the approaches dealing with Discernment politeness), the phenomenon that we call Potestas, even if it is not in essence a 'polite' phenomenon, but a behavioural pattern, determines a certain kind of relationship, and should be taken into account in order to correctly assess that type of interpersonal exchange. As such, we look to address its relationship with (Im)politeness Research. Several scholars have already sought to accommodate Power and Hierarchy in (Im)Politeness Research, yet fundamentally fail to convey its importance, as the majority of such attempts look to build these factors into Brown and Levinson's (1987) existing framework of face (i.e. Morand 1996, 2000; Yabuuchi 2006; see Locher 2004 for alternative approaches). However, as we will look to demonstrate, face and Power are two distinct, although overlapping, dimensions of interpersonal relations, and must be treated separately.

This paper is organised as follows. In Section 2 we introduce the concept of Power and its importance in interpersonal pragmatics and tackle the way politeness theories have managed to introduce the variable of Power in their analysis. We will pay special attention to Brown and Levison's (1987) classical model (Section 2.1), to Discernment politeness (Section 2.2), and to Terkourafi's Frame Theory (Section 2.3). In Section 3, we define our concept of Potestas, a second-order theoretical tool that we use to encapsulate the dynamics of the superior-subordinate relationship. Section 4 explores Potestas in the context of two ancient linguacultures, Late Egyptian (Section 4.1) and Old Latin (Section 4.2), and analyses the unfolding of Power in two different but comparable pieces of evidence (private letters in the case of Late Egyptian and literary works in the case of Old Latin). Finally, Section 5 discusses the findings of the research, points to the possibility of its wider applicability beyond ancient linguacultures and presents the conclusions of the paper. 


\section{Limitation of Power as an extra-linguistic factor within (im)politeness approaches}

As Spencer-Oatey (1997: 284) highlights, "unequal relationships occur in all societies", yet are particularly visible through a historic lens in historically remote cultures, since they tended to be far more stratified than modern Western societies. Power has long been considered a key concept in (Im)politeness Research and holds a central place within classical politeness theories such as Brown and Levinson (1987). ${ }^{2}$ Brown and Gilman (1960), in their study of the so-called T/V pronominal distinction (from Latin $t u / v o s)$, offered one of the most influential definitions of this concept for linguistic research: ${ }^{3}$

One person may be said to have power over another in the degree that he [sic] is able to control the behavior of the other. Power is a relationship between at least two persons, and it is nonreciprocal in the sense that both cannot have power in the same area of behavior. There are many bases of power - physical strength, wealth, age, sex, institutionalized role in the church, the state, the army or within the family. (Brown and Gilman 1960: 255)

Although today social Power is universally recognised as an important factor in interpersonal pragmatics, there is often the connotation within modern languages that Power is not a solely influencing factor (at least not the most influencing one), that it can be negotiated, and combined, nuanced or mitigated with other social variables. This stems in part from work by Emerson (1962), Foucault (1976: 124), Hofstede (1986: 307), and Searle (1995), which claim that "power comes from below", thus, as Leezenberg (2002: 899) clarifies, "it is not imposed from above in the force of domination by a sovereign, but arises from the collective action, or interaction, of the different social actors involved". This conception, characteristic of Social Psychological studies (see, for instance, Keltner et al. 2008), implies that Power is predominantly granted by the subordinates. This understanding of Power is inherently flawed, particularly for the ancient world, where social structures ensured and perpetuated the assignment of Power to certain individuals, and it was afforded through membership to social groups with economic and political pre-eminence. It is also inadequate for modern interactions, as encapsulated by Molm in the following quote.

Not only does mutual dependence bring people together, however; it also provides the structural basis for power: one actor's dependence is the source of another's power. To the extent that dependence is mutual, actors in social relations have power over each other. And, to the extent that their dependencies are unequal, their relation will also be unequal, in terms of the benefits that each contributes and receives. More powerful, less dependent actors will enjoy greater benefits at lower cost. (Molm 1997: 1)

Here, Molm (1997: 2) calls upon ideas from Social Exchange Theory, which places importance on ties of mutual dependency that underlie all social structures.

\footnotetext{
2 Harris (2003); Holmes and Stubbe (2003); Locher (2004); Mullany (2004); or the papers in Bousfield and Locher (2008), among others, deal with the intersection between Power and (im)politeness.

${ }^{3}$ For an overview, and a critical assessment of the variables Power and Distance in Linguistics and Social Psychological research, see Spencer-Oatey (1996). Regarding Power, see also Locher (2004: 9-43) and Vine (2004).
} 
It was originally Thibaut and Kelley's (1959) insight, however, that the structural condition that provides for the basis of structure exchange - the mutual dependence of actors on each other - also provides the basis for power. Relations of dependence bring people together (to the extent that people are mutually dependent, they are more likely to form relations and to continue them), but they also create inequalities in power (unequal dependencies give less dependent actors an advantage in the relation). (Molm 1997: 29)

This approach implies that Power focuses on the relationship between actors, resources - i.e. "capacities to perform behaviours that produce valued outcomes for others" (Molm 1997: 16) —, and the structure and process of the exchange. ${ }^{4}$ In the view of this theory, it is the low-risk/low-dependency actor who is perceived to have the most Power in this type of interactional exchange.

\subsection{Brown and Levinson and Power}

In Brown and Levinson's (1987) model Power is, together with social Distance (D) and the absolute Ranking of impositions in the particular culture $(R)$, one of the sociological variables that must be taken into account to assess the seriousness of an FTA. In their well-known formula to calculate the weightiness of a given FTA, that is, its seriousness, the three dimensions are placed on an equal footing, and the weightiness is calculated on a "simple summative basis" (Brown and Levinson 1987: 76). As they conceive it, "the function must capture the fact that all three dimensions $P, D$, and $R$ contribute to the seriousness of an FTA, and thus to a determination of the level of politeness with which, other things being equal, an FTA will be communicated" (ibid.). However, as we will try to demonstrate through the evidence of two ancient languages (Section 4), there are specific contexts, determined by a relationship status, in which $P$ is the overarching variable, causing the other two variables to become irrelevant (as well as the facewants of the low-Power individual).

Brown and Levinson's definition of Power is as follows:

$\mathrm{P}$ is an asymmetric social dimension of relative power, roughly in Weber's sense. That is, $\mathrm{P}(\mathrm{H}, \mathrm{S})$ is the degree to which $\mathrm{H}$ can impose his own plans and his own selfevaluation (face) at the expense of S's plans and self-evaluation. In general there are two sources of $P$, either of which may be authorized or unauthorized - material control (over economic distribution and physical force) and metaphysical control (over the actions of others, by virtue of metaphysical forces subscribed to by those others). In most cases an individual's power is drawn from both these sources, or is thought to overlap them. The reflex of a great $P$ differential is perhaps archetypally 'deference' [...]. (Brown and Levinson 1987: 77)

According to their view, these variables are sensitive to context and heavily depend on situational factors. For Brown and Levinson, Power interests fundamentally as a justification for deference. Thus, the difference in Power justifies the degree of elaboration and presence of politeness markers and deferential comportment, as in their exemplifying pair 'Excuse me sir, would it be all right if I smoke?' and 'Mind if I smoke?'. If $D$ and $R$ are constant and have small values, then

Our intuitions are that [1. Excuse me sir, would it be all right if I smoke?] might be said by an employee to his boss, while [2. Mind if I smoke?] might be said by the boss to the employee in the same situation. Here, then, $\mathrm{P}$ is the only variable that

\footnotetext{
${ }^{4}$ This is not cost/benefit exchange.
} 
changes from [1] to [2] (more exactly, $\mathrm{P}$ of $\mathrm{H}$ over $\mathrm{S}$ ), and this again lessens $\mathrm{W}_{x}$ which provides $S$ with the reasons for his choice between [1] and [2] for his linguistic encoding. (Brown and Levinson 1987: 80)

In both examples, a certain degree of politeness can be recognized, and even if the boss's utterance is less elaborated and includes less conventionalized politeness markers, it can still be considered polite, starting from the very fact that $\mathrm{s} / \mathrm{he}$ is asking a subordinate for permission to smoke. However, when the speaker's Power is notably higher than that of the addressee, then the speaker can bypass the need for faceredressive strategies. This is, in fact, one of the possibilities that these scholars foresee for doing a bald on-record act (this is the third possibility in the following quote):

Doing an act baldly, without redress, involves doing it in the most direct, clear, unambiguous and concise way possible (for example, for a request, saying 'Do X!'). [...] Normally, an FTA will be done in this way only if the speaker does not fear retribution from the addressee, for example in circumstances where (a) $\mathrm{S}$ and $\mathrm{H}$ both tacitly agree that the relevance of face demands may be suspended in the interests of urgency or efficiency; (b) where the danger to H's face is very small, as in offers, requests, suggestions that are clearly in H's interest and do not require great sacrifices of S (e.g., 'Come in' or 'Do sit down'); and (c) where $S$ is vastly superior in power to $\mathrm{H}$, or can enlist audience support to destroy H's face without losing his own.

(Brown and Levinson 1987: 69)

From these three possibilities, the one dealing with power differences is the only that implies the addressee's face-losing, or at least a lack of interest from the speaker towards the maintenance of the former's face. Even if Brown and Levinson do not explicitly identify these kinds of acts as impolite, the lack of politeness markers is somehow linked with rude behavior by these scholars. ${ }^{5}$ Nevertheless, as we will discuss in greater detail later in this paper, even if Power is maximum - a circumstance that in ancient linguacultures causes the other sociological variables to become irrelevant and allows the complete absence of politeness markers - , the superior's expected discursive practice has nothing to do with impoliteness, and cannot be characterized as such. Rather, in ancient societies, the imbalance of Power legitimizes the fact that the face of the subordinate becomes irrelevant.

\subsection{Discernment and Power}

The theorisation on the interpersonal phenomenon of Discernment stems from work conducted on Japanese honorifics in the 1980s (Hill et al. 1986; Ide 1989, 1992). This work, which arose to oppose the universalistic claims of the politeness model proposed by Brown and Levinson (1987), argued that the selection of an honorific was not strategic on the part of the speaker, but rather a "quasi-mandatory selection of the appropriate linguistic item based on the social context of the interaction" (Ridealgh and Jucker 2019: 57). Hence, in highly hierarchical societies, within interactions where Discernment takes place, the linguistic behaviour that indexes the social status of the hearer is prioritised over individual facework. The definition of face is contested, with Brown and Levinson's

\footnotetext{
${ }^{5}$ See, for instance, Brown and Levinson (1987: 97): "Another set of cases where non-redress occurs is where S's want to satisfy H's face is small, either because S is powerful and does not fear retaliation or non-cooperation from $\mathrm{H}[\ldots]$ or because $\mathrm{S}$ wants to be rude, or doesn't care about maintaining face." In the same vein, the presentation of keywords in the subject index ("politeness: absence of, see bald on-record, rudeness") seems to confirm this conceptual contiguity.
} 
(1978: 65-66) definition of the concept as an individual's public self-image, which "consists in a set of wants satisfiable only by the actions of others", often taking precedent (Sifianou 2011: 44). This is based on earlier work by Goffman (1972), who argued that face is the self-image a person projects, which is co-constructed in social interaction. As Sifianou (2011: 44) points out, both these concepts of face "recognise that for an interaction to succeed both respect of self and consideration for the other are needed". This requires a strategic use of Face-Enhancing Acts and FTAs to be utilised in a communicative event where the relationship dynamics are both fluid and continually renegotiated. This is not the case for Discernment, where hierarchy and (social) Power play an overarching role, restricting and framing the interaction. Although Discernment has previously been linked with the Japanese concept wakimae in academic literature (i.e. Matsumoto 1988, 1989, 1993), it is now considered that wakimae is the Japanese localization of Discernment. Thus, Discernment itself refers to an established theoretical, second-order politeness concept, which needs to be evaluated and considered on an individual cultural level (Pizziconi 2003; Kádár and Mills 2013; Kádár and Paternoster 2015; Ridealgh and Jucker 2019).

During the initial phase of research on Discernment, Hill et al. (1986, followed by Ide 1989) proposed that the opposing phenomenon to Discernment was Volition.

Complementary to Discernment is the aspect of politeness which allows the speaker a considerably more active choice, according to the speaker's intention, from a relatively wider range of possibilities. We call this Volition. (Hill et al. 1986: 348)

They went on to argue that Discernment and Volition were apparent in opposing degrees within Japanese and American-English politeness:

Our broad claim is that in all sociolinguistic systems there exists a sub-system for polite use of language which has at least two components. The first is the operation of Discernment, the second, Volition. Discernment must be considered as first because to ignore its requirements brings social punishment; that is, violations of the rules of Discernment offend others and thus hurt the speaker's social image. Within the sociolinguistic system, one must observe the social rule of Discernment. We might say that this (set of) rule(s) defines one's minimal obligations within the politeuse sub-system. Volition, on the other hand, defines a range of permissible modifications to the former: one may, but need not, adopt an alternate use in order to be acceptably polite. That is, the criteria or considerations addressed by Volition are optional from the stand-point of universal pragmatic strategy. The specific strategies by which individual sociolinguistic systems implement Volition will, of course, differ. (Hill et al. 1986: 351)

As Ide (1992: 303) herself stresses, "the major difference in the two types of linguistic politeness, wakimae and Volition, lies in the targets of politeness. In wakimae, politeness is oriented to social norms, whilst in Volition it is oriented to the face of the individual addressee". This opposition of Discernment and Volition has received strong criticism (Pizziconi 2003: 1500), and rightly so as it oversimplifies cultures and the polarization of their politeness systems (Kádár and Mills 2013: 137-140). Rather, as argued by Ridealgh and Jucker (2019: 65), Discernment and Volition need to be used together in order to critically assess politeness phenomena. This is particularly relevant for ancient languages, where often surviving data is sporadic and somewhat random, and so it is essential to use all politeness approaches in analyses and not prioritise one over another (Ridealgh 2016). 
Recently, Ridealgh and Jucker (2019: 65) proposed that "Discernment is an essential tool that helps us to assess and understand the subordinate-superior relationship dynamic" typical of many ancient cultures. This viewpoint places emphasis on the relationship itself between the interlocutors and how they perceive their relationship. This was something already addressed by Hill et al. in their original research in the 1980s, but not widely discussed:

Perceived Distance is the distance perceived by a speaker to exist between the self and a particular addressee in a particular situation and operating in a shared sociolinguistic milieu. This perception is the fundamental element, we believe, which determines a speaker's specific choices in his/her polite use of language. PD also covers the additional factor of degree of imposition (DI) of a request, which has the effect of modifying the linguistic choice that consideration of addressee status and situation, operating alone, would produce. Thus PD is the sum of the factors of addressee status and situation and DI. (Hill et al. 1986: 351)

What we seek to do in this paper is to expand on these arguments in order to correctly assess the concept of Discernment politeness, which linguistically materialises the perceived dynamic of any interpersonal relationship. Thus, when dealing with an unequal relationship, we should look not only at the subordinate-superior relationship, but also to the superior-subordinate dynamic. Both are complementary patterns around which any dyadic relationship with Power inequality pivots, especially in highly hierarchical societies. We argue that there is a distinct phenomenon, which we call Potestas, which helps to index the superior-subordinate dynamic. This phenomenon is complementary with deference and functions in the same way as it in regard to how it minimalizes facework and prioritises social status or Power.

\subsection{Frame Theory and Power}

In many ways, what we are arguing here about the culturally-specific dominance of Power within superior-subordinate relationship dynamics overlaps with Terkourafi's (1995, 2005) Frame Theory. Terkourafi (1999: 107) highlights that "an internal view of context and the notion of frames further allow us to account for 'politeness default values' assigned to linguistic forms in any given culture". Terkourafi goes on to develop this further:

The situated appropriateness of a linguistic device necessitates explicit reference to the norms operating at any one time in the community in question. To represent these norms, the notion of a frame is proposed as combining information about the situation with information about the appropriate use of language therein. Frames act as a pointer as to what constitutes normal circumstances in different situations for different communities. (Terkourafi 2005: 112-113)

Within her publications, Terkourafi (especially 1999, 2005) underpins Frame Theory with the role extra-linguistic factors play in determining how an interaction is deemed to be (im)polite, including the construction of FTAs and their weighting (Terkourafi 2005: 113). Power and Social Distance are two of these variables that are viewed and assessed together when making observations regarding polite usage of a situation:

Before attempting to account for the distribution of various SMs in the data using the formula $W x=D(S, H)+P(H, S)+R x$ (Brown \& Levinson 1987: 76), note that, by looking at requests performed for the first time, where the predicated act is 
expressed by an $\mathrm{AV} \mathrm{SAV}^{6}$ in the main clause of the utterance, we are in fact controlling for the variable of Ranking of the imposition. $\mathrm{Rx}$ is generally held constant at low values throughout the data, given that subjects were always aware of being recorded, which avowedly led them to avoid acts of high $\mathrm{R}$. This puts the onus of accounting for the results of the analysis on the other two variables, the Distance between the speaker and the hearer, and the Power of the hearer over the speaker. (Terkourafi 2005: 103)

Terkourafi is aware of the limitations of Brown and Levinson's (1987) approach, and she tries to overcome them:

The difficulties in operationalising Brown and Levinson's sociological variables of Power and Distance (and, by implication, their proposed formula for computing the weightiness of an FTAx), are likely to be alleviated when the various extra-linguistic variables discussed above as 'sources' of Power and Distance are considered jointly, rather than in isolation from each other. The onus of proof now lies on the side of those who would like to claim that Power and Distance thus understood (as clusters of extra-linguistic variables) are endowed with psychological reality above and beyond that of being the sum of their parts (as Brown \& Levinson would seem to imply, when they discuss the formula yielding $W x$ as "at least a partially accurate representation of cognitive process" (1987: 81), or when they attribute specific assumptions to the speaker regarding the social Distance between himself and the hearer, the Power of the hearer over him, and the culture-dependent ranking of the FTA in question (1987:74-75)). (Terkourafi 2005: 106-107)

In this way, Frame Theory can be used to explore and assess culturally specific behaviour grounded within localised and default value systems and how this is displayed through linguistic patterns (both strategic and unmarked) within interactions.

\begin{abstract}
Note that, because frames combine information about both the extralinguistic features of a situation, and the appropriate use of language therein, whichever of these is available first will give rise to expectations about the other. In this way, we can account for politeness assessments of utterances produced and interpreted in the course of an actual situation (where expectations are set up with recourse to the extra-linguistic features of the situation); but also, for politeness default values which cultures attribute to specific linguistic behaviours seemingly independently of context (where expectations are set up with recourse to linguistic information). Furthermore, once the similarity driving the matching of perceived information and information stored in memory is construed as a matter of degree, along the lines of G. Lakoff (1987), the proposed approach turns out to be constraining enough to account for diverging politeness assessments of formally equivalent linguistic devices by different cultures, while at the same time being general enough to allow for the observed creativity of linguistic politeness. (Terkourafi 2005: 111)
\end{abstract}

Where we find difficulty with the blanket use of Frame Theory and the linguistic phenomenon found in the ancient data is the interdependency of Power and Social Distance, and the foundational need to assess both of these aspects together and with equal consideration. Within the examples discussed below (Section 4), Power over-rides any other social variable that could influence the interaction. Although Terkourafi (2005: $105)$ does look to address this with regards to how much weighting social variables were given within an interaction, all variables are still considered within these analyses; the

\footnotetext{
${ }^{6}$ These acronyms refer to the grouping made by Terkourafi (2005: 103): Action Verb (AV) and Speech Act Verb (SAV).
} 
inclusivity of Frame Theory is perhaps too broad to discuss and explore one dominant independent social variable, although similar methodology approaches are certainly compatible.

\section{Defining the concept of Potestas}

For the ancient data, discussed below (Section 4), we look to identify superiorsubordinate interactions outside of the framework of Brown and Levinson (1987) within a broad range of texts, taking inspiration from Discernment politeness and the review of Power inequalities reflected in linguistic patterns. We use the term Potestas to encapsulate the life-depending reliance low-Power individuals have on high-Power superiors. This dependency is manifested in the linguistic behaviour intended to display hierarchical superiority towards someone who is in a lower position on the social scale. The word itself originates from Latin and is usually rendered as "power". The Oxford Latin Dictionary glosses potestas, in its first meaning, as "possession of control or command (over persons or things)", a level of control closely linked to the Roman magistracy system. Potestas also described the power of the father over his children and, in general, over all the members of his family (patria potestas). What is apparent from the Latin context, is that potestas was a quality largely granted by a public office or a certain social role. As Götter (2008) points out:

[E]very aspect of potestas was emphatically part of Rome's legal discourse. Roman law simultaneously guaranteed and limited its exercise. A good translation of potestas into English would therefore be 'the right to give orders'. Ideally, the assertion of potestas should not require physical coercion; rather, it was expected that a command from someone holding a magistracy, or performing a social role that was endowed with potestas, was met with obedience. (Götter 2008: 200) ${ }^{7}$

It could be argued that the word potestas describes a Latin emic concept of power regarding the functioning of Roman society, and that its meaning in that language is more a faculty than a behaviour, hence it cannot be used outside the limits of that very culture. Nevertheless, according to our proposal, in this paper we use Potestas as a theoretical second-order concept, to define a specific relational and linguistic behaviour vis-à-vis interpersonal dynamics: one that characterises the superior-subordinate relationship. Our concept of Potestas is based upon two key principles: 1) that the interaction exchange is shaped by Power and not individual facewants (which are irrelevant from the viewpoint of the superior) $;{ }^{8} 2$ ) that the ability of the high-Power individual to utilise a range of linguistic forms, many of which could be interpreted as FTAs outside of the unequal relationship, does not impact on the continued maintenance of the relationship. In the next two Sections, we will explore the linguistic manifestations of this concept in two remote languages: Late Egyptian and Old Latin.

We look here to highlight and coin the linguistic phenomenon Potestas, which we argue is part of Discernment and the opposing phenomenon to deference, as represented in Figure 1. We define Potestas as a concept that encapsulates reflective quasiauthoritative and dominant linguistic forms used by high-Power individuals within fixed

\footnotetext{
7 Nevertheless, as it will be illustrated in Section 4.2, in ancient Rome physical punishment collaborated in the holding of Potestas, at least within the relation master-slave.

${ }^{8}$ Even if allegedly the Power of the superior individual could be threatened, as happened in ancient China; see in Shen and Chen (2019) an analysis of the Chinese speech act of jian, which is considered a Power-Threatening Act.
} 
hierarchical cultural contexts. In contrast, deference can be seen to reflect quasimandatory and submissive linguistic features of low-Power individuals towards highPower individuals (Ridealgh and Jucker 2019). In neither of these cases is facework necessary for the maintenance of the relationship. So, the complementary relation between deference and Potestas functions as an alternative (or complementary) model to face management behaviour.

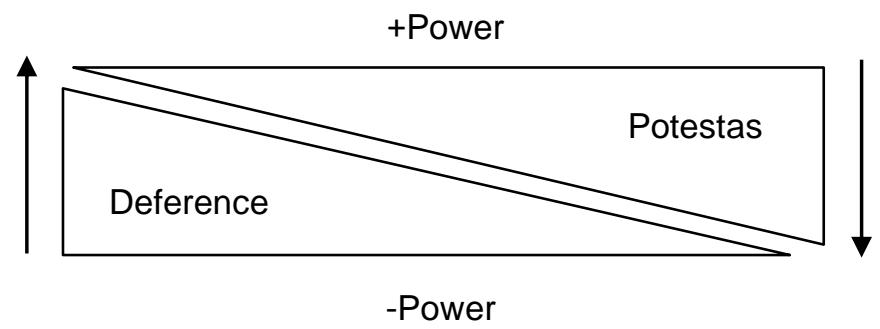

Figure 1. The complementarity Deference/Potestas model

Potestas, however, does present a quandary for (im)politeness researchers in the sense that its relationship to politeness is at first sight somewhat tenuous. Certainly, Potestas is part of interpersonal pragmatics, in that it has a key role to play in maintaining unequal relationships, yet we will argue here that, as a constituting part of Discernment, it also has a place within (Im)politeness Research as well.

An interesting feature of Potestas is that utterances which could be perceived as being FTAs in other contexts are not necessarily interpreted in the same manner within superior-subordinate relationships, especially those where the reliance on the superior individual is high. The relationship is maintained regardless of the intent or content of the utterance; the cognitive reception of the utterance is altered by the relationship dynamic. As such, and given the role of Power in the social structures of Antiquity, Potestas is not negatively marked within the frame of ancient societies, and can be considered as an expected discursive practice by superiors towards their subordinates.

\section{Exploring Potestas in context}

In this section, we present a situated analysis of Potestas within two different contexts from the ancient world: Late Egyptian and Old Latin, two distant and unrelated linguacultures, to demonstrate the applicability of this second-order theoretical tool to the study of ancient (im)politeness.

\subsection{Late Egyptian}

Ancient Egyptian language is one of the longest, continually attested languages in the world (Chinese is the other) and falls into the Afro-Asiatic language family. It first appeared in writing shortly before 3000BCE and then remained active until the eleventh century CE (Allen 2001: 1) and is of course a dead language today. During its period of use, Ancient Egyptian went through five evolutionary stages: Old Egyptian, Middle Egyptian, Late Egyptian, Demotic and Coptic, which is still used today within the Coptic Christian Church. It could also be written using two different writing scripts, the famous hieroglyphic and the lesser known hieratic (the exception to this is Coptic, which has its 
own alphabet derived from Greek). Within this paper, the focus of analysis is on texts written in Late Egyptian, which was used as a written form of the language between 1300-600BCE, although it was likely used as a spoken language from 1600BCE onwards (Allen 2001: 1; Junge 2005: 17-24).

The ancient Egyptian Late Ramesside Letters are a corpus of over seventy published letters written in Late Egyptian Hieratic, which date to the reign of the last New Kingdom King, Ramesses XI (c.1099-1069BCE). The letters reveal the daily lives and communications of a community of scribes and their families living on the Theban West Bank (modern-day Luxor). Within the letter corpus, social status of the interlocutor is reflected not only in the utterances included in the texts but also the construction of the letters themselves. Senders of letters who were socially superior to the recipient of their letter generally used a reduced formal introduction and a higher frequency of directives, whilst subordinate letter senders utilised longer formal introductions and more indirect or elaborated request acts (Ridealgh 2013a, 2016). This linguistic structure reflects the hierarchical nature of ancient Egyptian society, which saw the king as leader supreme, only usurped in power by the gods (ideologically, not necessary a reality at all times). Even on a more domestic level, a head of household would be responsible for everyone who lived under their domain, expected to protect, clothe and feed any who were household members, in exchange for their support in maintaining to daily activities of the household.

Potestas, as a linguistic phenomenon, is visible in letters sent by individuals who assume high-Power status between the interlocutors. Example (1) highlights a letter sent by the most senior individual included in the corpus, the General Piankh. Piankh's letters epitomise the superior style letter format: no formal introduction, just an address, directive-orientated, and no use of concluding formulae for finishing the letter (for subordinate letter styles, see Ridealgh 2013a). The example below represents a full letter sent by Piankh to a subordinate named Payshuweben in regard to the torture and murder of two Medjay (desert policemen) who were causing some type of civil unrest.

(1) (j)m(j)-ro mSo $n$ pr o\# onX wD\# snb $n$ rwD(.w) p\#.y-Sw-wbn Hno-Dd sDm=j md(w).t nb j.h\#b=k Hr=w p\# Dd j.jrj=k t\# md(w).t p\# mD\#.y 2 r-Dd Dd=w n\#y md(w).t j.jrj wo jrm $n D m$ sS Vry m-mj.tt $m t w=k$ h\#b $m t w=k$ Dj.t j.jnj.tw p\#y $m D \# . y 2$ r pr=j $m t w=k$ jnj $p H . w j$ $n \# y=w m d(w) . t m-S s$ zp-2 $m t w=k x d b \quad m t w=k X \# O=w$ p\# mw m grH jw m-djom $r(m) T n b$ p\#y t\# jm=w

The General of the Pharaoh, Life, Prosperity, and Health, to the Agent Payshuweben. Furthermore, I have heard all the matters you wrote about. As for mention you made of this matter of these two Medjay, saying "They spoke these words". Join up with Nedjemet and the Scribe Tjaroy as well. And send word. And bring these two Medjay to my house. And get to the bottom of their words quickly! And kill [them]. And throw [them] [into] the water at night. Do not let anyone in this land find out about it. ${ }^{9}$

The letter contains a string of directives without any mitigation, reinforced by words designed to act as time intensifiers (i.e. "quickly"). This was a normal occurrence for superior letter types, reflecting socially normative and conventionalised behaviour: good

9 Translations are the author's own as are any errors contained within; all translations are comparable with Wente's $(1967,1990)$. P. Berlin 10488: Černý (1939: 53-54); Wente (1967: 69; 1990: 183). 
subordinates must (promptly) complete the requests made to them by their superiors. Additionally, to the end of the letter is the utterance "Do not let anyone in this land find out about it" (jw m-dj om $r(m) T n b$ p\#y t\# jm=w), which acts as a threat or warning to not let anyone else know what has transpired. Requests themselves can often be viewed as FTAs, but threats certainly are, and both constitute an important part of the facework framework established by Brown and Levinson (1987). However, in this case, the FaceThreat, rather than needing to be mitigated, is simply not relevant within this relationship dynamic - Power is the overarching feature. Hence, this is not an FTA but rather part of superior linguistic features, which could be utilised when communicating with a subordinate individual. It is a linguistic display and reinforcement of Power.

A similar linguistic feature can be seen in the following Example (2), which represents a complete letter sent by the General Piankh to the Necropolis Scribe Dhutmose, referred to here by his nickname Tjaroy. In this example, the directives are followed by the phrase "Oh! You should know it", which appears slightly removed from the rest of the text in the letter to also visually reinforce the utterance.

(2) $p \#(j) m(j)-r o ~ m S o n ~ p r$ o\# onX $w D \#$ snb $n$ sS Vry $n$ p\# Xr Hno-Dd jX t\# md(w).t $n[. .]=.j n$ p\# $X r j . w n$ Dj.t oq.w n\# $m S w S$ orm $m t w=k$ tm Dj.t Dj.t=w $n=w$ oq. $w$ t\# wnw.t wnn so.t=j spr $r=k j w=k$ ptr p\# wn.w Dj.t [oq].w n n\# mSwS orw $m t w=k s w D . t=w n \# X-m n w r$ Dj.t sdj.y=f oq.w $n$ mSwS $m-d j . w j X r X=k s w$

The General of the Pharaoh, Life, Prosperity, and Health, to the Scribe of the Necropolis Tjaroy. Furthermore, what is the matter with the [...] of the Necropolis, who usually give bread-rations to the nearby Meshwesh, because you did not let them give the bread-rations at the (right) time? When my letter reaches you, you will find the person who usually gave the bread-rations to the nearby Meshwesh. And you should refer it to Akhmenu in order for him to take out the bread-rations for the Meshwesh from it. Oh! You should know it. ${ }^{10}$

Here the phrase "Oh! You should know it" $(j X r X=k s w)$ functions in the same manner as the previous example discussed. It is designed to highlight the social status of the sender of the letter, as well as motivate the recipient of the letter. It implicitly suggests that a socalled "good" subordinate would already know the request and have completed the tasks without directives needing to be issued by the superior individual. Again, this is not an FTA but a normative utterance for the superior-subordinate relationship dynamic, intended to encourage smooth completion of the task. As such, it seems to have become a conventionalised linguistic utterance for superiors.

For harmonious relations between superior and subordinate to be achieved certain expectations needed to be met, which have their foundation in the Power imbalance: superiors must look after their subordinates, and subordinates must fulfil all requests made of them, which benefit their superior (Ridealgh and Jucker 2019: 61-62). It is, in essence, a reciprocal relationship, although one defined and conceived by the elite, with both individuals gaining from it.

In Example (3) below, the same superior linguistic features are observable, but the letter also includes a critique of Dhutmose's behaviour and ability to complete tasks promptly ("What you have done is good. Continue to do likewise!", sw $m$-Ss $p \#$ j.jrj=k j.jrj=k m-mj.tt m$d w n z p-2)$, something not found in letters from subordinates to superiors. On one hand

10 P. BN 196 I: Černý (1939: 35); Wente (1967: 52; 1990: 184). 
Piankh praises Dhutmose's conduct and prompt completion of directives made to him, and, on the other hand, continues to use established superior language formats to linguistically reinforce the difference in their status.

(3) $p \#(j) m(j)$-ro $m S$ So $n$ pr o\# onX $w D \#$ snb $n$ sS Vry Hno-Dd $s D m=j m d(w) . t[n b] j . h \# b=k n=j$ $H r=w$ p\# $h \# b$ j.jrj=k $r-D d$ jry=j oror $w p(w . t) n b$ sHn.w nb $n$ p\#y=j nb ntj $r-j w d=j$ bn $t w=j$ $n n y j n=k$ sw $m$-Ss $p \# j$ j.jrj=kj.jrj=k $m-m j . t t ~ m-d w n$ zp-2 wnn So.t spr $r=k j w=k$ oror $w p(w . t)$ $n b$ sHn nb jnk $n t j$ r-jwd $=k m t w=k j r=w ~ m-d j g m=j n=k$ bt\#. $w j X r X=k s w$

The General of the Pharaoh, Life, Prosperity, and Health, to the Scribe of the Necropolis Tjaroy. Furthermore, I have heard all the matters you wrote to me about. Regarding what you wrote saying: "I completed every task and every commission of my lord, which I was assigned and I did not tire" so you said. What you have done is good. Continue to do likewise! When my letter reaches you, you should complete every task and every commission of mine, which you are charged. And you should carry them out. Do not let me find any fault with you. Oh! You should know it. ${ }^{11}$

It is not just the letters written by Piankh that reflect this superior style of communication, Dhutmose is also able to adopt the same stylistic features discussed above with subordinate individuals. In a letter to his son Butehamun, he includes the following utterance providing judgement on Butehamun's actions in Example (4).

(4) $X r$ m-dj $t \# m d w n$ t\# qd.t 2 nb.w j.Dd=j [... $n=k j m]$ st $r p \# p j j w=k$ tm Dj.t=w jm $y \# t w=j$ jy.tr $[$... $]=j \operatorname{tm} g m=w$ bn nfr $p \# y$ j.jrj=k

Now regarding the matter of the 2 qd.t of gold. I said to you "Put it in the base". You did not place it there. Oh! I have returned to [...] but I have not found them. It is not good what you did. ${ }^{12}$

Within the letters Dhutmose sends his son, negative critiques of Butehamun's actions are rare. The intimacy of their father-son relationship provides a buffer somewhat to the more socially distant and formal superior-subordinate dynamic, which can host a range of critical linguistic forms (Ridealgh 2020). This is visible, for example, in a letter Dhutmose sends to an unknown junior scribe, partially deputising for Dhutmose. This letter contains a series of rebukes regarding the actions (or lack thereof) of a subordinate individual. Within the superior-subordinate dynamic, Dhutmose can say whatever he likes to rebuke the individual and there is no recourse for response (Ridealgh 2013b). The language is designed to reassert the social dynamic and embedded expected behaviour, as well as motivate the individual to complete the actions issued to them.

(5) Hno-Dd y\# jX p\# $m d w . t m-d j=k m t w=k$ tm $s D m m t w=k$ [...] $s H n n$ pr-o\# onX $w D \#$ snb $p \# y=k n b \quad n f r n t j t w=k j m=f$

Furthermore: Indeed! What is the use of speaking to you, if you do not listen, and that you remain idle in this commission from Pharaoh, your good lord, in which you are engaged?

(6) $\quad X r D d(=j) n=k j .[w D j] N . j-s w-c b k p \# y=k s S j m$ Hn=f jrm o\# EHw.tj-ms.w sS Jw=f-n-Jmn jm jn.tw $n \# j t$ bw-pwy sDm $n=j$

11 P. BN 197 III: Černý 1939: 34; Wente 1967: 52; 1990: 184.

12 P. BN 199 V-IX + 196 V + 198 IV, v.2-4: Černý 1939: 5-7; Wente 1967: 21-24; 1990: 186187. 
Now I said to you "Send Nessobek, your scribe, and have him go together with the Doorkeeper Dhutmose and the Scribe Efnamun to bring the grain". But you did not listen to me.

(7) $\quad p t r$ bw jr=k sDm n=j Jmn H\#.t=k jnn n\#y=k sHn.w oS\# r=k bn jw=krX Sm m p\#y sHn n pro\# onX wD\# snb

Behold! You don't listen to me. May Amun be before you. If your commissions are too many for you, you know you cannot walk away from the commissions from Pharaoh, Life, Prosperity, and Health. ${ }^{13}$

In sum, within the ancient Egyptian examples, there are set linguistic forms which could be utilised depending on the social status of the recipient of the letter. High-Power individuals utilised a much broader range of linguistic and structural features, including threats, without needing to take into account the facewants of the recipient - they do not exist within the nature of this dynamic. It is also apparent in these examples that certain phrases, such as "Oh! You should know it" had become conventionalised and part of the expected language use of superior individuals, and, no doubt, were imbued with deeper cultural meaning now lost.

\subsection{Old Latin}

Latin, belonging to the Italic branch of the Indo-European linguistic family, is also one of the most widely attested languages, and was the first "World language", widespread all over the globe as the language of the Roman Empire and later of the Catholic Church (Clackson 2011: 1). Even if nowadays it is a dead language ("Latin is a corpus language, known only through written documents, and no one who could genuinely be described as a native speaker of Latin has been alive for the last millennium"; ibid.: 2), an important number of modern languages derive from it - the Romance languages, such as Italian, French, Spanish, Portuguese, Romanian, etc. Its earliest attestations can be dated to the seventh century BCE and it is still used by the Holy See. Latin is usually divided into the following stages: Archaic and Old Latin, Classical Latin, Late Latin, Medieval Latin and Neo-Latin.

Old Latin, and particularly the language of Roman Comedy (see Karakasis 2014), provides us with further linguistic evidence of the concept of Potestas, this time coming from the Roman society of $3^{\text {rd }}-2^{\text {nd }}$ BCE. The study of Roman society and behaviour (including linguistic behaviour) through the comedies of Plautus (c.254-c.184BCE) entails several methodological problems, since these are works based upon plays of Greek New Comedy, and they present strongly stereotyped characters, and fixed dramatic structures and plots. However, linguists very often consider Roman Comedy as a valid source for the study of Latin Pragmatics and (im)politeness phenomena. ${ }^{14}$.

Again, one of the most apparent manifestations of Potestas in Latin is the utterance of directive speech acts devoid of any mitigating device, which could be interpreted as indifference towards the addressee's (negative) face according to traditional politeness approaches (see above, Section 2.1). The following is an example of a set of orders given by a master, Euclio, to his servant, a woman called Staphyla:

(8) [EVC.] Profecto in aedis meas me apsente neminem

${ }_{13}$ P. BN 198 III, rt.3-v.4: Černý 1939: 68-70; Wente 1967: 81-82; 1990: 172-173.

${ }^{14}$ See, for instance, Barrios-Lech (2016), Unceta Gómez (2016), lurescia (2019); Unceta Gómez (2018) presents the state of the art of (Im)politeness Research in Latin. 
uolo intro mitti. Atque etiam hoc praedico tibi:

si Bona Fortuna ueniat, ne intro miseris.

STA. Pol ea ipsa credo ne intro mittatur cauet,

nam ad aedis nostras nusquam adit quamquam prope.

EVC. Tace atque abi intro. STA. Taceo atque abeo. [...] (Plautus, Aulularia 98-103)

'[EUC.] In short, I don't want anybody to be let into my house in my absence. There's another point I want to make: if Good Fortune herself comes, don't let her in.

STA. I think she herself avoids being let in, because she's never come anywhere near our house.

EUC. Be quiet and go inside.

STA. Yes, I am quiet and I am going.' ${ }^{15}$

The claim of Euclio's superiority, evident in his chosen means of expression - the modal verb uolo 'I want', the performative use of the verb praedico 'to advise or warn (to)', the bare imperative to silence and move her away, among others -, clearly contrasts with the mitigation of the assertion of the slave's response by means of the verb credo 'I think', or the expression of obedience in the last line.

Alongside orders, threats are also one of the most apparent means of performing Power (see Limberg 2008; Biscetti 2015). ${ }^{16}$ In Example (9), from the comedy Amphytruo, the master Amphitruo deploys a battery of menaces to his servant Sosia, who is trying to explain that he has seen himself at their house (in reality, it is the god Mercury impersonating Sosia, just as Jupiter has impersonated Amphitruo to have intercourse with the latter's wife, Alcumena).

(9) AMPH. Age i tu secundum. SOS. Sequor, supsequor te.

AMPH. Scelestissimum te arbitror. SOS. Nam quam ob rem?

AMPH. Quia id quod neque est nec fuit nec futurum est mihi praedicas. SOS. Eccere, iam tuatim

facis, ut tuis nulla apud te fides sit.

AMPH. Quid est? Quo modo? lam quidem hercle ego tibi istam

scelestam, scelus, linguam abscidam. SOS. Tuos sum,

proinde ut commodum est et lubet quidque facias;

tamen quin loquar haec uti facta sunt hic,

numquam ullo modo me potes deterrere.

AMPH. Scelestissume, audes mihi praedicare id, domi te esse nunc, qui hic ades? SOS. Vera dico.

AMPH. Malum quod tibi di dabunt, atque ego hodie

dabo... SOS. Istuc tibi est in manu, nam tuos sum.

AMPH. Tun me, uerbero, audes erum ludificari? (Plautus, Amphytruo 551$565)$.

'AMPH. Come on, walk behind me.

SOS. I'm following you, I'm following you closely.

AMPH. I think you're a hardened criminal.

SOS. But why?

\footnotetext{
${ }^{15}$ Text and translations of Plautine texts are those of de Melo (2011a, 2011b).

${ }^{16}$ The same could be said about insults, such as scelestissume 'hardened criminal' in (9); see Gaide (2001: 961).
} 
AMPH. Because you're telling me something that doesn't exist, hasn't existed, and won't exist.

SOS. Look, now you're behaving in your typical way, not trusting your servants at all.

AMPH. What's that? How so? I'll cut you this villainous tongue of yours this instant, you villain.

SOS. I'm yours; you can do anything that's convenient and to your taste; still, you can never deter me in any way from saying what really happened.

AMPH. You hardened criminal, you dare tell me that you, who are here, are at home now?

SOS. I'm telling the truth.

AMPH. The bad time which the gods will give you today, and I too...

SOS. That's in your hand: I'm yours.

AMPH. You whipping post, do you dare to poke fun at me, your master?'

Notwithstanding the slave's insistence in the veracity of his words, he accepts with resignation his master's superiority and his capacity (and legitimacy) to inflict upon him the punishment commensurate with his decision ("I'm yours; you can do anything that's convenient and to your taste" Tuos sum, proinde ut commodum est et lubet quidque facias; "That's in your hand: I'm yours" Istuc tibi est in manu, nam tuos sum), whereas Amphitruo keeps on speaking in a menacing manner to obtain a certain response. In this case, Sosia's behaviour is essential for the progress of the plot but does not question his master's authority. The following verses, pronounced by the old man Periplectomenus, clearly illustrates this point: ${ }^{17}$

(10) PER. Seruiendae seruituti ego seruos instruxi mihi, hospes, non qui mi imperarent quibusue ego essem obnoxius: si illis aegre est mihi [id] quod uolup est, meo remigio rem gerunt, tamen id quod odio est faciundum est cum malo atque ingratiis. (Plautus, Miles gloriosus 745-748).

'PER. I've schooled my slaves to serve me, my guest, not to order me around or for me to be obliged to them. Even if they're upset at what I enjoy, they do their job under my direction and they still have to do what they hate, with beatings and against their wishes.'

The comedies also show a frequent phenomenon of inversion of hierarchical relations, in which young masters entrust themselves to their clever slaves to help them to fulfil their romantic aims. This phenomenon is illustrated in (11): $:^{18}$

(11) LEO. Auscultate atque operam date et mea dicta deuorate. primum omnium seruos tuos nos esse non negamus; sed tibi si uiginti minae argenti proferentur, quo nos uocabis nomine? ARG. Libertos. LEO. Non patronos? ARG. Id potius. LEO. Viginti minae hic insunt in crumina, has ego, si uis, <nunc> tibi dabo. ARG. Di te seruassint semper, custos erilis, decus popli, thensaurus copiarum, $[\ldots]$

17 Another interesting example, Stultitia est ei te esse tristem quoius potestas plus potest. (Plautus, Casina 282) 'It's stupidity to be sulky with someone who has greater authority', is a clear admonition, uttered by a freeman to a slave, on the necessity of respecting and obeying those who are invested with power.

${ }^{18}$ As McCarthy (2000) has extensively analysed, in Roman comedy two modes of representation of hierarchical relations coexist: a "naturalistic mode" and a "farcical mode". 
hic pone, hic istam colloca cruminam in collo plane.

LEO. Nolo ego te, qui erus sis, mihi onus istuc sustinere.

ARG. Quin tu labore liberas te atque istam imponis in me?

LEO. Ego baiulabo, tu, ut decet dominum, ante me ito inanis.

$[\ldots]$

LEO. Hanc, cui daturu's hanc, iube petere atque orare mecum. (Plautus, Asinaria 649-662)

'ARG. Listen, you two, pay attention, and devour my words. First of all we don't deny that we're your slaves. But if you get twenty silver minas, by what name will you call us?

ARG. Freedmen.

LEO. Not patrons?

ARG. That rather.

LEO. There is twenty minas here in this wallet. (holds it up) I'll give it to you now if you want to.

ARG. May the gods prosper you always, guardian of your master, glory of the people, storehouse of riches, [...]. Put it here, place this wallet here plainly on my neck.

LEO. I don't want you to bear this burden for me, since you're my master.

ARG. Why don't you free yourself from the strain and put this onto me?

LEO. I will carry it, you, as is appropriate for a master, should go in front of me empty handed.

[...]

LEO. Tell the woman you're going to give it to ask for it and to plead with me.'

As can be understood from Example (11), the master's dependence on the servant (Leonida) to achieve his goals explains the fact that the former (Argyrippus) assumes a subservient language (see, for instance, the intensive expression of gratitude through a blessing and hyperbolic compliments), and the latter clearly expresses his (contextual and transitory) Power, although with a sarcastic explicit expression of the kind of relationship they all are in. This inversion of hierarchies confirms (even if mockingly) the existence of characterizing features in the language of both superiors and inferiors.

All these examples illustrate the more assertive and powerful linguistic styles of superiors, ${ }^{19}$ and the disregard to the "face" of the slaves, the main existence of which was even denied in that society by the elite. As Kaster (2005: 23) puts it, "slaves - at least according to the ideology of Roman slavery - have no autonomous volition, hence no actual self, hence no face to maintain or lose". This negation, according to Stewart (2012), strengthens and legitimates the Roman slave system. As she points out:

The slave-holder creates and promotes representations of the slave and slave behavior that legitimate his domination. The slave system cannot recognize or represent the slave as an autonomous subject because to do so fundamentally contradicts the logic of slavery. The effectiveness of slavery as a system of domination depended on naturalizing the overwhelming, coercive power as both temperate and moral, as normal and natural. In other words, both the master's honorable capacity to exercise unilateral coercive authority and the slave's capacity — as a subordinated yet still thinking subject — to act morally as a subject

${ }^{19}$ See also Barrios-Lech (2016: 215-232), who presents other pieces of evidence of the language of domination in Roman comedy. 
only when obedient to the master were fundamental to the success of the Roman

slave system. (Stewart 2012: 8)

Thus, in sum, it can be said that there exists in Old Latin certain linguistic expressions that index a hierarchical superiority of the speaker with regard to the addressee. This behaviour, assuming the "non-existence" of the slave's face, is not, technically speaking, a show of impoliteness, given that there is no place for the consideration of certain acts as Face-Threatening. Certainly, it could be argued that low-Power individuals do indeed have face, but they are not in a position to protest. Still, even if the preserved evidence probably offers a very limited picture of the actual situation, given that it was written by members of the elite in closed connection with their own values, the fact that the evidence we have access to presents that value system heavily supports the idea that in ancient societies the Power of the elite had a radical importance.

\section{Discussions and concluding remarks}

Deference and Potestas, as contrary but complementary sides of Discernment, are reflexes of behavioural and linguistic normative dimensions oriented towards the reinforcement and perpetuation of existing Power relations. As such, the low-Power individual has no linguistic pathways or opportunities to renegotiate the Power dynamic: it is culturally fixed. Yet the utterance is not interpreted as impolite either, the high-Power individual has neither caused offence that would damage their own face nor damaged the low-Power individual's face, simply because within this dynamic, the low-Power individual does not possess a public face - in essence, their facewants, and face itself, are over-ridden by Power. This is of course dependent on the relationship. An individual, as highlighted above with the Egyptian data, can be both a superior and a subordinate, adopting the differing linguistic expectations and "rights" of these roles. The Latin data used here is slightly different in that, on the one hand, the social relations in Plautus' comedies are rigidly and schematically depicted, and, on the other hand, the stock character of the astute slave, upon whom a young person in love depends, usually takes the reins and assumes a powerful style of talk for the sake of comic relief. This comic inversion of hierarchies confirms, as we have seen, the descriptive capacity of Potestas as a theoretical second-order concept in interpersonal pragmatics.

From a linguistic perspective, the relationship inequality is manifested in the language used to host this dynamic and of course to foster and maintain it. This relationship maintenance is not realised by a need to meet individual facewants, but rather the expected application of culturally appropriate language between high-Power and lowPower individuals or actors. This is a direct result, as we said before, of the Power imbalance between superior and subordinate individuals, where the high-Power individual does not need to satisfy the facewants of the low-Power individual. It is simply not necessary for the successful continuation of the relationship. Rather, this is dependent on the resources each party can provide, particularly the high-Power individual.

Despite the criticism they received, due to its grounding in Brown and Levinson's (1987) classical model, Politeness Research has predominantly focused on the strategic features of politeness, somehow obscuring the normative dimension underlying a certain linguistic behaviour, a gap partly covered by the theory of Discernment politeness (see above, Section 2.2). The focus on ancient linguacultures allows us to re-emphasise the importance of ignored behavioural patterns conceived within those societies as social 
norms. In essence this means that, although certain utterances can be deemed as FTAs under Brown and Levinson's (1987) model (see Section 2.1), within the model of Potestas, no face aggravation occurs as the low-Power individual is devoid of it, as we see in both the Egyptian and Roman contexts. If, from an emic perspective (politeness 1 ), this linguistic pattern was not understood as impolite, we cannot include it under the label "impoliteness" (even if, as observed in the examples above, there is an apparent lack of politeness). Thus, the linguistic behaviour encapsulated in the concept of Potestas cannot be considered, strictly speaking, impolite, rather it belongs to the realm of "nonpoliteness" or politic behaviour (in Locher and Watts' 2005 terminology).

A point for further discussion beyond what we argue here stems from how Power is viewed in second order politeness approaches. Within the dynamics of many interpersonal interactions within ancient societies and languages, as exemplified in Section 4, there was no pretention to mitigate the expression of Power; on the contrary, the custom was to emphasise it, given the ideological functions of some linguistic features. In contrast, modern European languages tend to allow for the negotiation of Power, with the exception of certain fossilised expressions of submission, which have become conventionalised linguistic forms used regardless of the hierarchical relation between the interlocutors (Held 1999). The linguistic and cultural displays of Potestas seems to have faded, perhaps in part due to the increasing egalitarianism of Western societies, the prevalence of symmetry in social relationships (see, e.g., Schwartz 1994; Morand 1996, 2000), and the identification of authoritarianism with impoliteness. ${ }^{20}$ As Locher (2004: 37) puts it, "[a] society's ideologies, however, can also obscure the exercise of power to such an extent that it is no longer recognized as power". Once the expression of Power became a "taboo", deference strategies evolved predominantly to express social Distance. It could even be argued that this perception of the linguistic display of Power as unacceptable reached the theorization of politeness phenomena, ${ }^{21}$ which has largely disregarded the linguistic behaviour of superiors - as Yabuuchi (2006) highlights, Brown and Levinson refused to reflect in their model the importance of hierarchy. Nevertheless, it is our claim that a powerful style of talk, which neglects some (pretended universal) guidelines of facework, can be simply understood as a show of the expected behaviour of powerful individuals in a given setting. Thus, introducing the notion of Potestas into (Im)politeness Research allows for a more nuanced analysis of interactions, especially those which fall between the boundaries of politeness and impoliteness.

Unequal Power relations may be more palpable in ancient cultures (given their stronger and explicit hierarchical ideology) but are certainly recognizable in modern societies. In contrast to Locher's (2004: 33) view, who proposes that "a person's higher status does not in itself mean that he or she can automatically exercise power over a person with lower status. It is thus an oversimplification to equate power with hierarchical status", we claim that, in ancient societies (but certainly not only within them), both categories are closely related, the latter being the main support for the former. The correlation between

\footnotetext{
20 It would be worth diachronically exploring the origins of this behavioral pattern, which could maybe have to do with some Christian values, such as 'mercy' (Biscetti 2015: 301-302). A comparison with non-Western linguacultures and linguistic habits regarding Power would also shed some extra light to the concept of Potestas.

${ }^{21}$ The normative dimension of second-order Politeness Research is criticised by Eelen (2001), for example.
} 
impoliteness and Power has been well stated by recent research (see the papers collected in Bousfield and Locher 2008). It has also been observed that certain institutions favour a "sanctioned" aggressive or impolite behavioural approach (Watts 2003: 259-269), such as the army (see Bousfield 2008) ${ }^{22}$ or, more generally speaking, the workplace (Schnurr et al. 2008: esp. 216). In these situations, however, it must be admitted that "when we wield power we are not necessarily being impolite" (Bousfield 2008: 150). In several interactional contexts, an asymmetric distribution of Power, especially in highly institutionalized settings, implies a linguistic behaviour enacting Power, which includes omitting facework strategies, but is not necessarily viewed as impoliteness either (see also Haugh 2013). Potestas could therefore be a useful theoretical tool to tackle this kind of linguistic behaviour in modern languages and societies, and to offer an integrated account of Power within (im)politeness theories, a possibility that needs further research.

In conclusion, we propose that Potestas is a phenomenon that encapsulates an expected discursive practice by superiors towards their subordinates that is not polite nor impolite, and has its foundation in the indexing of Power in superior-subordinate relationships. The impact of Power within this dynamic is more straightforward to determine in ancient languages, as hierarchy was a dominant feature of ancient societies and Power was a fixed and non-negotiable feature rooted in specific social institutions and cultural practices. Thus, analysing historically remote cultures allows us to consider that, under certain circumstances, Power is a static and predictable variable, which, in the case of Historical (Im)politeness Research, facilitates the task of making predictions about linguistic behaviour of individuals. This is also true in modern societies, where, bosses, judges, policemen, teachers, doctors, parents and any other individual (institutionally or contextually) invested with Power can assume "powerful styles of talk" (Bradac and Street 1989/90), that, even if getting into dynamics of negotiation of public image, do not necessarily threaten the addressee's face. Therefore, we can include Potestas as part of the politic behaviour of specific cultures, of specific communities of practice, or even specific relations between individuals. We can also conclude that Historical (Im)politeness Research and the focus on discursive practices and linguistic styles of remote cultures can illuminate - perhaps more straightforwardly than the intercultural comparison (as, e.g., Spencer-Oatey 1997) — the understanding of certain linguistic behaviours in modern languages, whose interpretations have sometimes been affected by ideological issues.

\section{References}

Allen, James P., 2001. Middle Egyptian: An Introduction to the Language and Culture of Hieroglyphs. Cambridge: Cambridge University Press.

Assmann, Jan, 1990. Ma`at. Gerechtigkeit und Unsterblichkeit im alten Ägypten. Munich: C.H. Beck.

\footnotetext{
22 As Bousfield (2008: 143) states, "[T]he British Army philosophy (like the philosophies of many military forces the world over) is predicated on the belief that the hierarchy of power is necessarily rigid, concrete and inflexible - for the good of all within the service and for its effectiveness as an organisation. As such, the recruits' understanding of who is on top of the power structure, and who on the bottom, needs to be very clear and totally unambiguous".
} 
Barrios-Lech, Peter, 2016. Linguistic Interaction in Roman Comedy. Cambridge: Cambridge University Press.

Biscetti, Stefania, 2015. Power, (im)politeness and aggressiveness in early modern masterservant relations (1660-1759). Journal of Early Modern Studies 4: 287-314.

Bradac, James J. and Richard L. Street, Jr. 1989/90. Powerful and powerless styles of talk: A theoretical analysis of language and impression formation. Research on Language and Social Interaction 23: 195-242.

Brown, Penelope, and Stephen C. Levinson, 1987. Politeness. Some Universals in Language Usage. (Studies in Interactional Sociolinguistics 4). Cambridge: Cambridge University Press.

Brown, Roger, and Albert Gilman, 1960. Pronouns of power and solidarity. In T. A. Sebeok (ed.). Style in Language. Cambridge, MA: MIT Press, 253-276.

Bousfield, Derek, 2008. Impoliteness in the struggle for power. In Derek Bousfield and Miriam Locher (eds.). Impoliteness in Language: Studies on its Interplay with Power in Theory and Practice. Berlin/New York: De Gruyter, 255-280.

Bousfield, Derek and Miriam Locher (eds.), 2008. Impoliteness in Language: Studies on its Interplay with Power in Theory and Practice. Berlin/New York: De Gruyter

Černý, Jaroslav, 1939. Late Ramesside Letters. Bibliotheca Aegyptiaca 9. Brussels: Fondation égyptologique reine Élisabeth.

Conlan, Christopher, 2005. Face threatening acts, primary face threatening acts, and the management of discourse: Australian English and speakers of Asian Englishes. In Robin Lakoff and Ide Sachiko (eds.). Broadening the horizon of linguistic politeness. Amsterdam: John Benjamins, 129-144.

Clackson, James, 2011. Introduction. In James Clackson (ed.), A Companion to the Latin Language, Wiley-Blackwell: Malden, MA/Oxford/Chichester, 1-6.

De Melo, Wolfgang, 2011a. Plautus. Amphitryon. The Comedy of Asses. The Pot of Gold. The Two Bacchises. The Captives. Cambridge, MA: Harvard University Press.

De Melo, Wolfgang, 2011b. Plautus. The Merchant. The Braggart Soldier. The Ghost. The Persian. Cambridge, MA: Harvard University Press

Eelen, Gino, 2001. A Critique of Politeness Theories. Manchester/Northampton, MA: St. Jerome. Emerson, Richard M., 1962. Power-dependence relations. American Sociological Review 27.1: $31-41$.

Foucault, Michel, 1976. Histoire de la Sexualité I: La Volonté de Savoir. Gallimard: Paris. (English translation: The History of Sexuality, vol. I: An Introduction. Vintage Books: New York, 1980).

Gaide, Françoise, 2001. A propos des interactions verbales dans le théâtre de Plaute. In Claude Moussy (ed.), De lingua latina, novae quaestiones. Actes du Xè Colloque International de linguistique Latine. Louvain/Paris/Sterling, VA: Peeters, 959-970.

Gotter, Ulrich, 2008. Cultural differences and cross-cultural contact: Greek and Roman concepts of power. Harvard Studies in Classical Philology 104: 179-230.

Haugh, Michael, 2013. Disentangling face, facework and im/politeness. Pragmática Sociocultural / Sociocultural Pragmatics 1.1: 46-73.

Harris, Sandra, 2003. Politeness and Power: Making and responding to 'requests' in institutional settings. Text: An Interdisciplinary Journal for the Study of Discourse 23.1: 27-52.

Held, Gudrun, 1999. Submission strategies as an expression of the ideology of politeness: Reflections on the verbalisation of social power relations. Pragmatics 9.1:21-36.

Hill, Beverly, Sachiko Ide, Shoko Ikuta, Akiko Kawasaki and Tsunao Ogino, 1986. Universals of linguistic politeness: Quantitative evidence from Japanese and American English. Journal of Pragmatics 10: 347-371.

Hofstede, Geert, 1986. Cultural differences in teaching and learning. International Journal of Intercultural Relations 10: 301-320.

Holmes, Janet, and Maria Stubbe, 2003. Power and Politeness in the Workplace. A Sociolinguistic Analysis of Talk at Work. London: Longman.

Ide, Sachiko, 1989. Formal forms and Discernment: two neglected aspects of linguistic politeness. Multilingua 8.2/3: 223-248. 
Ide, Sachiko, 1992. On the notion of "wakimae": Toward an integrated framework of linguistic politeness. In: Michiko Takeuchi (ed.). Kotoba no mozaiku. Collection of Papers in Honor of Professor Natsuko Okuda. Tokyo: Mejiro Linguistic Society, 298-305.

lurescia, Federica, 2019. Credo iam ut solet iurgabit: Pragmatica della lite a Roma. Gottingen: Vandenhoeck \& Ruprecht.

Junge, Friedrich, 2005. Late Egyptian Grammar: An Introduction. Translated by David Warburton. 2nd ed. Griffith Institute Publications. Oxford: The Griffith Institute.

Kádár, Dániel Z., and Sara Mills, 2013. Rethinking Discernment. Journal of Politeness Research 9.2: 133-158.

Kádár, Dániel Z., and Annick Paternoster, 2015. Historicity in metapragmatics: A study on "Discernment" in Italian metadiscourse. Pragmatics 25.3: 369-391.

Kádár, Dániel Z., and Kim Ridealgh, 2019. Introduction. Journal of Historical Pragmatics 20.2: 169-185.

Karakasis, Evangelos, 2014. The language of the palliata. In Michael Fontaine and Adele C. Scafuro (eds.), The Oxford handbook of Greek and Roman Comedy. Oxford/New York: Oxford University Press, 555-579.

Keltner, Dacher, Gerben A. Van Kleef, Serena Chen and Michael W. Kraus, 2008. A reciprocal influence model of social power: Emerging principles and lines of inquiry. Advances in Experimental Social Phychology 40: 151-192.

Leech, Geoffrey, 2014. The Pragmatics of Politeness. Oxford: Oxford University Press.

Leezenberg, Michiel, 2002. Power in communication: implications for the semantics-pragmatics interface. Journal of Pragmatics 34: 893-908.

Limberg, Holger, 2008. Threats in conflict talk: Impoliteness and manipulation. In Derek Bousfield and Miriam Locher (eds.). Impoliteness in Language: Studies on its Interplay with Power in Theory and Practice. Berlin/New York: De Gruyter, 155-179.

Locher, Miriam, 2004. Power and Politeness in Action. Disagreements in Oral Communication. Berlin/New York: Mouton de Gruyter.

Locher, Miriam, 2015. Interpersonal Pragmatics and its link to (im)politeness research. Journal of Pragmatics 86: 5-10.

Locher, Miriam and Richard J. Watts, 2005. Politeness theory and relational work. Journal of Politeness Research 1.1: 9-33.

Matsumoto, Yoshiko, 1988. Reexamination of the universality of face: politeness phenomena in Japanese. Journal of Pragmatics 12: 403-426.

Matsumoto, Yoshiko, 1989. Politeness and conversational universals: observations from Japanese. Multilingua 8: 207-221.

Matsumoto, Yoshiko, 1993. Linguistic politeness and cultural style: observations. In Clancy, P.M. (ed.) Japanese and Korean Linguistics. Vol. 2. Stanford, CA: Stanford University, 55-67.

McCarthy, Kathleen, 2000. Slaves, Masters and the Art of Authority in Plautine Comedy. Princeton, NJ: Princeton University Press.

Molm, Linda, 1997. Coercive Power in Social Exchanges. Cambridge University Press: Cambridge.

Morand, David, 1996. Dominance, Deference, and Egalitarianism in Organizational Interaction: A Sociolinguistic analysis of power and politeness. Organization Science 7.5: 544-556.

Morand, David, 2000. Language and power: an empirical analysis of linguistic strategies used in superior-subordinate communication. Journal of Organizational Behaviour 21: 235-248.

Mullany, Louise, 2004. Gender, politeness and institutional power roles: Humour as a tactic to gain compliance in workplace business meetings. Multilingua 23.1-2: 13-37.

Pizziconi, Barbara, 2003. Re-examining politeness, face and the Japanese language. Journal of Pragmatics 35: 1471-1506.

Ridealgh, Kim, 2013a. 'Yes Sir!' An Analysis of the Superior/Subordinate Relationship in the Late Ramesside Letters. Lingua Aegyptia: Journal of Egyptian Language Studies 21: 181-206.

Ridealgh, Kim, 2013b. You Do Not Listen to Me! Facework and the Position of 'Senior' Scribe of the Necropolis? Journal of Ancient Civilization 28: 22-40. 
Ridealgh, Kim, 2016. Polite like an Egyptian? Case studies of politeness in the Late Ramesside Letters. Journal of Politeness Research 12.2: 245-266.

Ridealgh, Kim, 2020. 'Look after him in the night' - Exploring the linguistic manifestation of the father/son relationship dynamic. In Shih-Wei Hsu, Vincent Pierre-Michel Laisney, and Jan Moje (eds.). Ein Kundiger der in die Gottesworte eingedrugen ist: Festschrift für den Ägyptologen Karl Jansen-Winkeln zum 65 Geburstag. Münster: Zaphon, 263-272.

Ridealgh, Kim, and Andreas Jucker, 2019. Late Egyptian, Old English and the re-evaluation of Discernment politeness in remote cultures. Journal of Pragmatics 144: 56-66.

Schnurr, Meredith Marra and Janet Holmes, 2008. Impoliteness as a means of contesting and challenging power relations in the workplace. In Derek Bousfield and Miriam Locher (eds.). Impoliteness in Language: Studies on its Interplay with Power in Theory and Practice. Berlin/New York: De Gruyter, 211-230.

Schwartz, Shalom H., 1994. Beyond individualism/collectivism. New cultural dimensions of values. In Uichol Kim, Harry C. Triandis, Çigdem Kâğitçibaşi, Sang-Chin Choi and Gene Yoon (eds). Individualism and Collectivism. Theory, Method, and Applications. London: Sage, 85-119.

Shen, Xingchen and Xinren Chen, 2019. Doing Power Threatening Acts (PTAs) in ancient China. An empirical study of Chinese jian discourse. Journal of Historical Pragmatics 20.1: 132156.

Sifianou, Maria, 2011. On the concept of Face and Politeness. In Francesca Bargiela-Chiappini and Dániel Kádár (eds.). Politeness across Cultures. Basingstoke: Palgrave Macmillan, 4258.

Simpson, William Kelly, 2003. The Literature of Ancient Egypt: An Anthology of Stories, Instruction and Poetry. New Haven: Yale University Press.

Searle, John, 1995. The Construction of Social Reality. Free Press, New York.

Spencer-Oatey, Helen, 1996. Reconsidering Power and Distance. Journal of Pragmatics 26: 124.

Spencer-Oatey, Helen, 1997. Unequal relationships in High and Low power distance societies: A comparison of Tutor-Student role relations in Britain and China. Journal of Cross-Cultural Psychology 28.3: 284-302.

Stewart, Roberta, 2012. Plautus and Roman Slavery. Malden-Oxford-Chichester: WileyBlackwell.

Sweeney, Deborah, 2001. Correspondence and Dialogue: Pragmatic Factors in Late Ramesside Letter Writing. Ägypten und Altes Testament: Studien zu Geschichte, Kultur und Religion Ägyptens und des Alten Testaments 49. Wiesbaden: Harrassowitz Verlag.

Terkourafi, Marina, 1999. Frames for politeness: A case study. Pragmatics 9.1: 97-117.

Terkourafi, Marina, 2005. An argument for a frame-based approach to politeness: Evidence from the use of the imperative in Cypriot Greek. In Robin Lakoff and Ide Sachiko (eds.). Broadening the horizon of linguistic politeness. Amsterdam: John Benjamins, 99-116.

Thibaut, John W., and Harold H. Kelley, 1959. The Social Psychology of Groups. New York: Wiley.

Unceta Gómez, Luis, 2016. Congratulations in Latin Comedy: Types and functions. Journal of Politeness Research 12.2: 267-290

Unceta Gómez, Luis, 2018. Gli studi sulla (s)cortesia linguistica in latino. Possibilità di analisi e proposte per il futuro. Studi e Saggi Linguistici 56.2: 9-37.

Vine, Bernadette, 2004. Getting Things Done at Work. The discourse of power in workplace interaction. Amsterdam/Philadelphia: John Benjamins.

Watts, Richard J., 2003. Politeness (Key Topics in Sociolinguistics). Cambridge: Cambridge University Press.

Wente, Edward Frank, 1967. Late Ramesside Letters. Oriental Institute of Chicago Studies in Ancient Oriental Civilisation 33. Chicago: University of Chicago Press.

Wente, Edward Frank, 1990. Letters from Ancient Egypt, edited by E. Meltzer. Society of Biblical Literature: Writings from the Ancient World 1. Atlanta: Scholars Press. 
Yabuuchi, Akio, 2006. Hierarchy politeness: What Brown and Levinson refused to see. Journal of Intercultural Pragmatics 3.3: 323-351. 